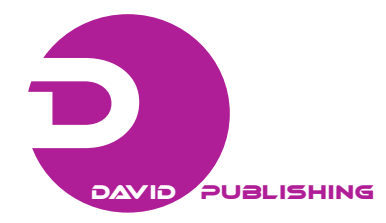

\title{
Implementing Life Cycle Costing in Malaysian Construction Industry: A Review
}

\author{
Nor Azizah Mohammed Rum and Zainal Abidin Akasah \\ Department of Building and Construction Engineering, Faculty of Civil and Environmental Engineering University of Tun Hussein \\ Onn Malaysia, Batu Pahat 86400, Malaysia
}

\begin{abstract}
The construction industry is a sector that contributes a lot to the economic growth of Malaysia, as it is developing rapidly similar in fashion to other developing countries around the world. In line with the 9th Malaysia Plan, development in Malaysia must meet current and future needs to achieve sustainability in economic development, as well as functioning as a social and environmental responsibility for prosperity without compromising the needs of future generations. To ensure that the government's objective is met, construction industry should implement the LCC (life cycle costing) method in structure and infrastructure projects so as to not cause losses to the industry itself and to the government. Through LCC, factors contributing to, and the associated cost of maintenance works for a building are identified at the design stage to obtain a more accurate projection of the total cost. This paper describes the LCC as a vital element in the construction industry since this method can drive quality improvement by taking into account the comprehensive cost of a project. The main aim of this paper is to aid in understanding the application of the LCC concept for the construction industry, particularly for the maintenance phase. This paper also identifies LCC processes involved in a building construction project and subsequently provides recommendation on appropriate measures to implement LCC in the construction industry in Malaysia.
\end{abstract}

Key words: Construction industry, life cycle costing, operation, maintenance.

\section{Introduction}

Construction industry is a sector that contributes to economic growth [1, 2]. This industry is regarded as a stimulus to the development of other industries by introducing Malaysia as a developing country in the developed world. In addition, construction industry is crucial in the efforts and vision of the government to achieve sustainable development by the year 2020 . Sustainable development requires a balance between economic growth, social expansion and environmental protection, and thus can be achieved by addressing and emphasizing related environmental issues, in addition to economic gains and social obligations [3]. As the economy improves the construction industry will follow suit in particular for economic construction, as it

Corresponding author: Nor Azizah Mohammed Rum, MEng. candidate, research field: civil engineering. E-mail: jijah22@yahoo.com. is closely linked to the development of other sectors such as manufacturing and services [1]. This effect that construction industry has on other industries was proven during Malaysia's recession period as it provided the nation with the opportunity to sustain its economy [2]. However, production in the construction sector is different from other sectors as it is not homogenous and each construction project is considered unique and has its own value. In addition, the output of a construction project or design has to meet external influences viz. sociology, politics, culture and economy [4].

According to the Economic Report of Malaysia [5], development of construction industry was largely supported by the increase in civil engineering and non-residential property immediately following the implementation of developmental projects under the 9MP (9th Malaysia Plan).

As a developing country, the construction industry in Malaysia involves detailed management on various 
matters including but not limited to, construction materials, machinery, technology, labour, and implementation, and it does so in a way that it can realize its aspirations as well as fulfilling the people's basic needs [5]. The role of this industry in economic development of Malaysia was highlighted in the aforementioned report where it contributed to 8.7 percent of the GDP (Gross Domestic Product) growth in the first quarter of 2010, consequently making it one of the major contributors.

However, more sophisticated approach is indeed possible for the design and construction of building and/or facilities through a combination of economic theory and computer technology, in particular in terms of cost to design and build [6-8]. Building owners should expand their perspective to include the cost of operation, maintenance, repair, replacement, and disposal of their respective properties [9, 10], a measure that can be achieved by implementing LCC method.

LCC is the process of identifying and documenting the initial cost and future cost of the development project during the lifetime of the building [9, 11, 12]. Through this method, factors contributing to, and the maintenance costs of a building are accounted for at the design stage to obtain a more accurate projection of the total cost, which can subsequently lead to the optimisation of costs via application of Value Management for specified quality levels [13].

\section{Life Cycle Costing}

\subsection{Life Cycle Cost Definition}

Different terms have been used to refer to this concept, where older resources may refer to it by the term cost in use, changing over the years to LCC (life cycle costs), and later to WLC (whole life costing) and WLA (whole life appraisal) to better represent the concept [14]. The present term whole life appraisal defines the systematic consideration of all relevant costs, revenues and performance associated with the acquisition and ownership of an asset over its physical, economic, functional, service and design life. It minimizes total expenditure through proper appraisal of costs that are incurred throughout the facility's life. Fig. 1 shows the LCC planning at different stages during a building lifespan.

As such, LCC can serve as a valuable technique to predict and assess the cost performance of constructed assets, and thus aid in determining whether a project meets the client's performance requirements [15].

In short, LCC is pivotal to the asset management process as an input to its alternative evaluation via Economic Appraisal, Financial Appraisal, Value Management, Risk Management and Demand Management. LCC adds all the costs over the asset's life period and enables an evaluation on a common basis for the period of interest. This enables decisions on acquisition, maintenance, refurbishment or disposal to be made in the light of full cost implications [16].

The importance of LCC is further supported by the fact that large sums of money are required to keep a facility in operation and in good conditions. Generally in some cases, running cost could be as high as $40 \%$ of the capital cost or even more. Anecdotal evidences have suggested that only about $10 \%$ of the total cost is actually required to complete the project, while $90 \%$ of the total project cost is associated with maintenance

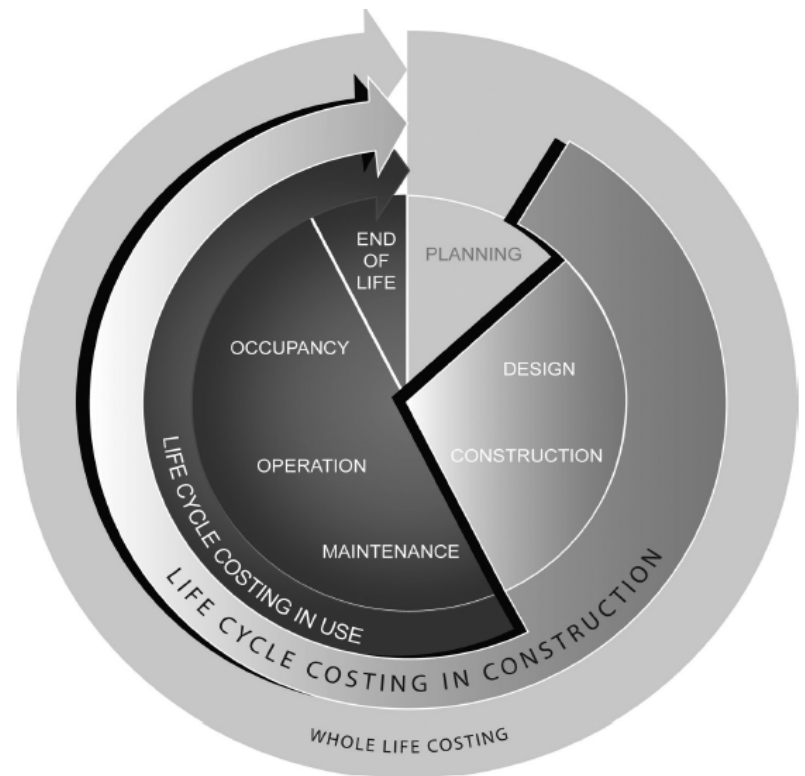

Fig. 1 Life cycle cost planning at different stages [15]. 
and running operations [17]. The effects of the maintenance and running cost on the project are so evident that any attempt to overlook them would be at the detriment of the client and in fact, to the professional competence of the design and construction teams [14].

\subsection{LCC Model}

According to Total Asset Management, LCC model is an accounting structure containing terms and factors which enable estimation of an asset's component costs. A number of commercially available models can be used for LCC analysis [16]. However, in some cases it may be appropriate to develop a model for a specific application. In either case, an LCC model should:

(1) Represent the characteristics of the asset being analysed including its intended use environment, maintenance concept, operating and maintenance support scenarios and any constraints or limitations;

(2) Be comprehensive enough to include and highlight the factors relevant to the asset LCC;

(3) Be easily understood to allow timely decision-making, future updates and modification;

(4) Provide for the evaluation of specific LCC elements independent of the other elements.

Before selecting a model, the purpose of the analysis and the information it requires should be identified. The model should also be reviewed with respect to the applicability of all cost factors, empirical relationships, constants, elements and variables. Fig. 2 shows that the LCC process fundamentally involves:

(1) Assessing costs arising from an asset over its life cycle;

(2) Evaluating alternatives that have an impact on this cost of ownership.

An asset can be any item that has a value to an organisation over time, such as buildings, physical plants and equipment and computer software. Consideration of all these costs is important even if they are funded from different sources within an organisation [18].

One may describe LCC models as predictive in nature and characterize a stochastic process involving many parameters such as interest rates and reliability. Nevertheless, irrespective of the types of models used for LCC analysis they all must be visible, transparent and effective in representing systems, equipment, subsystems or devices [19].

\subsection{LCC Method}

Cost estimating is a popular activity as various kinds of cost have to be estimated each day. The estimated cost has to be as close as possible to its actual value, otherwise it may lead to a consequence of a severe degree. Since the success or failure of an organization

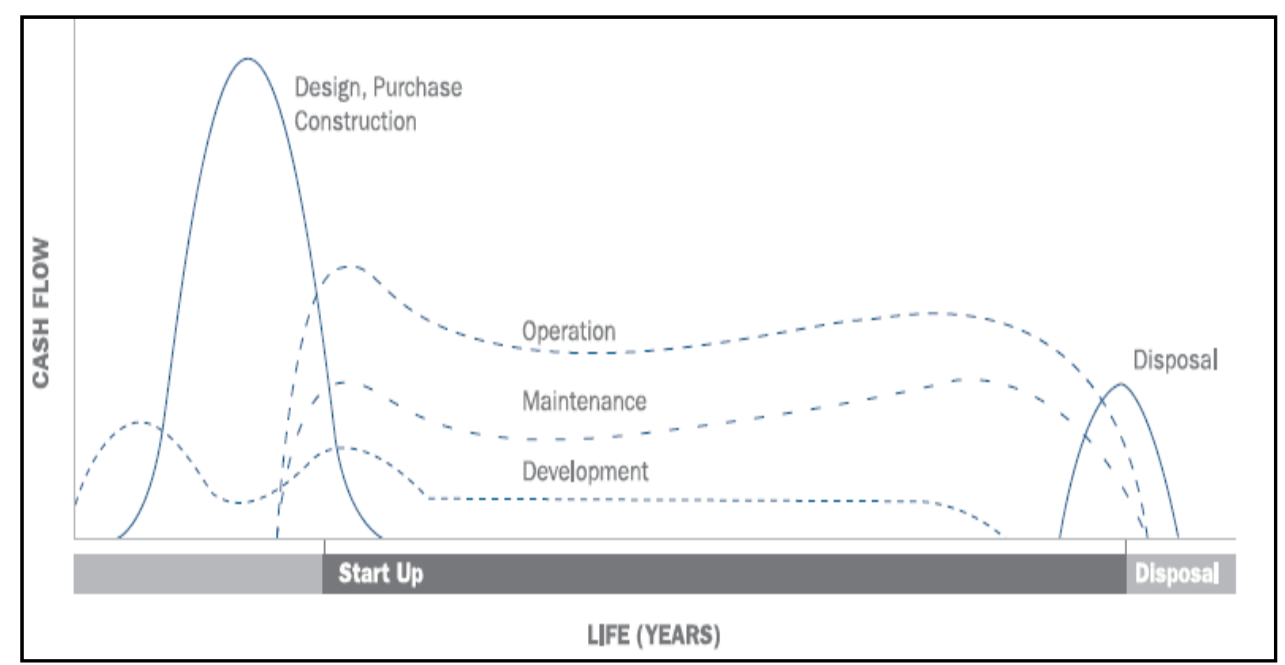

Fig. 2 Life cycle cost concept [18]. 
may depend on the quality of cost estimates, those working in cost-estimating area have to come up with several different cost estimation methods, models and procedures [19, 20].

Various literature resources have suggested that the most suitable approach for LCC in the construction industry is the NPV (net present value) method. Existing mathematical LCC models based on NPV have various advantages and disadvantages as they differ in the breakdown of costs' elements. The model from the American Society for Testing Materials as shown in Eq. (1) for instance, distinguishes between energy and other running cost, which is useful in adopting different discount rates for different cost items [21].

$$
N P V=C+R-S+A+M+E
$$

where,

$C=$ investment costs

$R=$ replacement costs

$S=$ the resale value at the end of study period

$A=$ annually recurring operating, maintenance and repair costs (except energy costs)

$M=$ non-annually recurring operating, maintenance and repair cost (except energy costs)

$E=$ energy costs

According to Arja, Souce and Souyri, LCC can be calculated at any phase of the building life by assessing the overall cost of the building under construction or already in service [22]. There are several basic steps involved in LCC [23] as listed below:

(1) Identify what has to be analyzed and the time period for the project life study along with the appropriate financial criteria;

(2) Focus on the technical features by way of the economic consequences to look for alternative solutions;

(3) Develop the cost details by year considering memory joggers for cost structures;

(4) Select the appropriate cost model, e.g., simple discrete, simple with some variability for repairs and replacements, and complex with random variations;
(5) Acquire the cost details;

(6) Assemble the yearly cost profiles;

(7) For key issues prepare breakeven charts to simplify the details into time and money;

(8) Sort the big cost items into a Pareto distribution to consider the need for further study;

(9) Test alternatives for high cost items, e.g., what happens if maintenance cost is $10 \%$ more than planned, etc.;

(10) Study uncertainty/risk of errors/alternatives for high cost items as a sanity check and provide feedback to the LCC studies in iterative fashion;

(11) Select the preferred course of action and plan, and defend the decision with graphic aids.

\subsection{Integrated Life Cycle Design}

Integrated life cycle design is still at a phase of rapid development, and this is the start of the final formulation of a new integrated design process and methodology which in future will serve as a general design culture [21]. This method integrates the design, management and maintenance planning of buildings and civil infrastructures into a comprehensive life time engineering [24]. The main aspects included in the model are displayed in Fig. 3. The model might be able to address several facets of uncertainties, going beyond a traditional LCC model.

\section{Operations and Maintenance}

Maintenance refers to any activity or a combination of actions that cover the technical aspects and management functions undertaken to maintain, preserve or recover something to its original condition. It is also a combination of any actions taken to repair or relocate an item or tool to an acceptable situation [25]. Furthermore, it also refers to the work other than daily and routine cleaning necessary to maintain the performance of the building fabric and its services [26].

One the most difficult decisions faced by facility/asset owners regarding maintenance is the timing of different types of maintenance work in order 


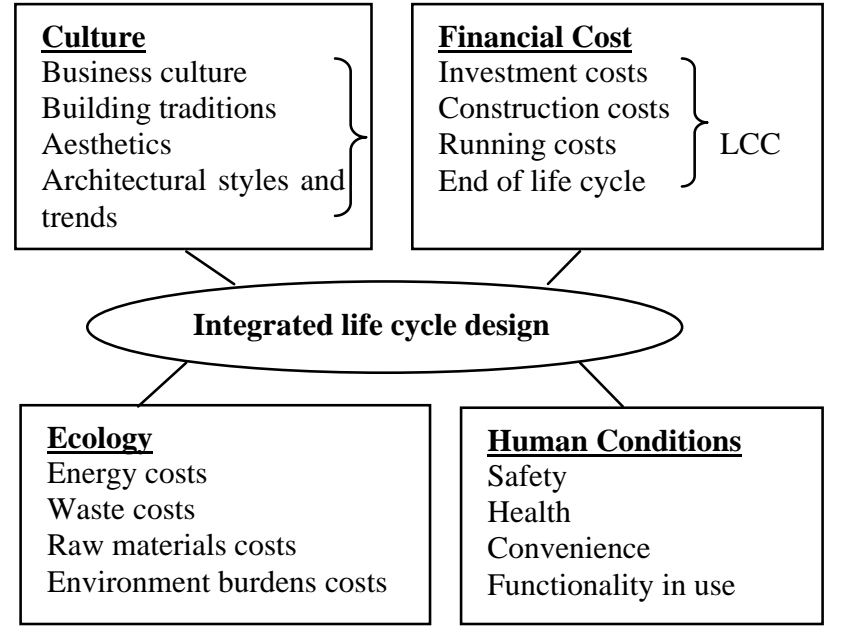

Fig. 3 Integrated life cycle design [21].

to keep facilities up to a proper and acceptable state of repair. Several policies are available, ranging from a short-term temporary repair to the undertaking of a full-scale renewal. The choice of action depends on a number of factors and as a result significant reductions in maintenance costs are likely to result from a life cycle approach, namely:

(a) The cost of different types of repair;

(b) The rate of deterioration;

(c) The relationship between the physical life of the repair and required physical, functional and economic life of the facility;

(d) The disruption and disturbance to the building occupants and time required for the repair.

Maintenance repair consists of three stages viz. inspection, diagnosis and constructional or remedial action. Maintenance works can be classified under the following subheading [14].

\subsection{Maintenance of the Main Structure}

The main structure is exposed primarily to the natural elements and maintenance work will probably involve inspection and routine planned maintenance.

\subsection{Maintenance of the Finishing/Fixture/Fittings}

The finishing suffers from wear and tear by the occupants and will require periodic renewal.

\subsection{Maintenance of the External Works}

The external works will require extensive maintenance via grass cutting, replacement of shrubs and trees and paving.

\subsection{Maintenance of the Plumbing, Mechanical and} Electrical Services

Each of the services elements has its own maintenance requirements. While planned and preventive works are usually undertaken, frequent corrective maintenance dependent upon the building's age will be needed.

\subsection{Modernisation and Adaptation}

This will often take place on a planned basis at a certain point in the facility's life.

\subsection{Redecorations}

Internal and external redecorations will be necessary on a planned basis.

\section{Research Aims}

The main aim of this paper is to understand the LCC concept for application in the construction industry in Malaysia, especially in maintenance phase. In addition, this paper will also identify LCC processes in building construction and provide recommendations to implement LCC in the construction industry in Malaysia. The importance of implementing LCC in construction industry especially during the operation and maintenance phase are also highlighted.

\section{Scope of Study}

The scope of this case study is limited to institutional buildings in Malaysia, i.e., department buildings at UTHM (Universiti Tun Hussein Onn Malaysia), Johor. The scope is chosen due to feasibility reasons, as well as the fact nowadays new institutional buildings are featuring more sustainable designs than conventional institutional/residential buildings in Malaysia. 


\section{Research Methodology}

Approaches used are searching through printed materials and electronic media to facilitate the literature study, as well as distribution of questionnaires, interviews and brief discussion with the supervisor and selected respondents to facilitate the empirical study. The study is implemented gradually based on Fig. 4.

\subsection{Research Population/Sample}

In this study, a questionnaire was distributed to certain person-of-interest, such as the occupants of the building, contractors, developer and building consultants to obtain statistically useful information about the topic. It is the only feasible way to reach a number of reviewers large enough to allow a statistical analysis of the results.

\subsection{Proposed Data Collection Method}

The interviews were conducted along with the questionnaire and site survey to obtain detailed investigative information and data related to maintenance issues, as well as the implementation of the LCC approach to control the costs incurred during the building's lifetime.

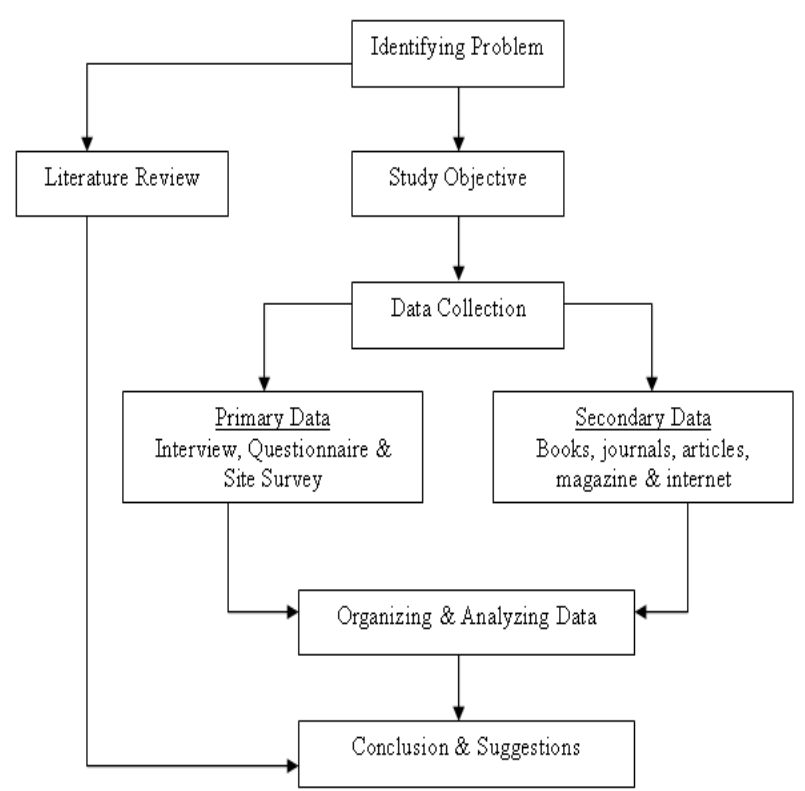

Fig. 4 Research Methodology Flow Chart.

\subsection{Data Analysis}

The data obtained from the questionnaire will be analysed by using SPSS (statistical package for social sciences) while the cost-related information from interview and site survey were discussed for more detailed result.

\section{Results/Outcomes}

Based on the study, it was found that a majority of building owners/managers are not aware or not implementing LCC in the management strategies. This is mostly attributed to their reluctance to commit to a change in their management policy/strategy as well as an increment in management cost associated with LCC (e.g., hiring personnel with expertise in LCC). Furthermore, most are not aware of the benefits of a properly implemented LCC in the long run.

Though some government projects have already implemented LCC (projects costing above RM $500,000.00$ ), it is suggested that governmental bodies take a more active role in encouraging and perhaps enforcing the implementation of LCC in non-government development projects. Government/Semi-government organizations such as the CIDB (Construction Industry Development Board) have a high potential of playing a prominent role for this purpose.

In reiteration of Arja et al. [22], LCC analysis can be further developed and extended for application in different types, or services/functions of buildings such as building design and costing, decision making and planning process.

\section{Discussion}

From the literature review, even though LCC have been described and established widely for various types of facilities, there is still a lack in application especially for different types of building. In Malaysia, LCC application is very limited, in particular in facilities management sector [27]. 
The Malaysian government has also highlighted that public infrastructure maintenance has to be focused in order to develop a better maintenance culture. This maintenance culture plays a big role in building management as it involves the overall cost [27]. LCC can be thus adopted as a tool to achieve effective budget allocation [27].

\section{Conclusions}

As a conclusion, LCC is a concept which involves consideration of economic concept of time and value of money, which in turn may be used to compare the amount of money that will be spent over an extended number of years [27].

As such, this study has highlighted the benefits and advantages not only to the building management but to the government bodies involved in the construction sector, as certain problems in maintenance phase can be overcome through the LCC approach.

Through properly implemented LCC, productivity as well as the value of investments can be increased indirectly, while maintenance costs may be reduced.

\section{Acknowledgments}

I would like to sincerely thank Associate Professor Dr. Hj Zainal Abidin Akasah as my supervisor for the feedback throughout the research and the writing process of this paper. My profound appreciation to UTHM (Universiti Tun Hussein Onn Malaysia) in giving me the opportunity to do this study, as well as my family and friends for their continuous support and encouragement.

\section{References}

[1] Construction Industry Development Board Malaysia, CIMP (Construction Industry Master Plan) Malaysia 2006-2015 CIMP, Malaysia: Construction Industry Development Board Malaysia, 2007, pp. 1-6.

[2] S. Gerald, Newsletter of the Construction Industry Development Board Malaysia (CIDB), CIDB News Issue 2 (2007) 3.
[3] Construction Industry Development Board Malaysia, Strategic Recommendations for Improving Environmental Practice in Construction Industry, 2007.

[4] M. A. Yusof and I. Omar, Economic Cycle Analysis and Construction Industry in Malaysia, Ph.D. Thesis, University of Teknologi Malaysia, 2007. (in Malay)

[5] Ministry of Finance Malaysia, Economic Report 2010/2011.

[6] B. S. Dhillon, Life Cycle Costing, Gordon and Breach Science Publishers, United States of America, 1989.

[7] J. S. Kirk and J. A. Dell'lsola, Life Cycle Costing for Design Professionals (2nd ed.), McGraw-Hill, Inc, United States of America, 1995.

[8] C. H. Nam, Practical approaches to the application of life-cycle civil engineering for infrastructure in Korea, Life-Cycle Civil Engineering 1 (2008) 21-34.

[9] M. R. Sirin, Theory of Engineering Economics, Parit Raja, University of Tun Hussein Onn Malaysia (UTHM), Batu Pahat, 2007. (in Malay)

[10] R. R. Venkataraman and J. K. Pinto, Cost and Value Management in Projects, John Wiley \& Sons, Inc, New Jersey, 2008.

[11] C. Bahr, K. Lennerts, Maintenance-LCC analysis based on real data, Life-cycle Civil Engineering 1 (2008) 783-786.

[12] A. A. A. Azis, BFB 4093: Life Cycle Cost, Power Point, Universiti Tun Hussein Onn Malaysia, 2009 (Chapter 4).

[13] CIDB (Construction Industry Development Board Malaysia), CIDB News Issue 2 (2010) 5.

[14] R. Flanagan and C. Jewell, Whole Life Appraisal for Construction, Blackwell Publishing Ltd, Oxford, 2005.

[15] British Standards Institution, Building \& Constructed Assets-Service Life Planning, Part 5: Life Cycle Costing, BS 15686-5, London, 2008.

[16] TAM (Total Asset Management), Life Cycle Costing Guideline, New South Wales Treasury, Sydney, 2004.

[17] A. L. Olanrewaju, M. F. Khamidi, A. Idrus and K. Shobowale, A comparative analysis of value engineering and life cycle costing techniques: A literature Review, in: 4th International Conference on Built Environment in Developing Countries, 2010.

[18] Better Practice Guide, Life Cycle Costing, Australian National Audit Office, 2001.

[19] B. S. Dhillon, Life Cycle Costing for Engineers, Gordon and Breach Science Publishers S.A, Amsterdam, 2009.

[20] E. Korpi and T. A. Risku, Life cycle costing: A review of published case studies, Managerial Auditing Journal 23 (3) (2008) 240-261.

[21] S. Jutta, Life Cycle Cost Calculation Models for Buildings, University of Technology, Lulea Sweden, 2007. 
[22] M. Arja, G. Sauce and B. Souyri, External uncertainty factors and LCC: A case study, Building Research \& Information 37 (3) (2009) 325-334.

[23] H. P. Barringer and P. E. Barringer, Associates, Inc., Life cycle costs \& reliability for process equipment, in: Proc. of the 8th Annual Energy Week Conference \& Exhibition, Texas: American Petroleum Institute, Houston, 2003, pp. 1-22.

[24] S. Asko, Integrated Life Cycle Design of Structures, MPG Books Ltd, Great Britain, 2002.
[25] B. Wood, Building Maintenance, Wiley-Blackwell, Singapore, 2009.

[26] British Standards Institution, Guide to Building Maintenance management, BS 8210, London, 1986.

[27] M. A. P. Hishamuddin, H. R. K. Shazlializa, A. Fatin and J. D. Jibril, Stochastic life cycle costing model of cost effectiveness in facilities, Management 1 (2010) 244-254. 